\title{
Relações entre caracteres de cenoura para sistemas de cultivos orgânico e convencional
}

\author{
Giovani Olegário da Silva ${ }^{1}$, Jairo Vidal Vieira ${ }^{2}$
}

\section{RESUMO}

De acordo com a estratégia de seleção e o ganho que ela proporcionará, pode-se orientar, de maneira mais efetiva, um programa de melhoramento, bem como predizer o sucesso do esquema seletivo adotado. O objetivo deste trabalho foi verificar a estabilidade das relações entre caracteres fenotípicos a partir de populações de cenoura cultivadas em sistemas de produção orgânico e convencional. Os experimentos foram conduzidos na Embrapa Hortaliças, DF. Duas populações de cenoura em fase de melhoramento e quatro cultivares comerciais foram plantados em novembro de 2007 no campo nos dois sistemas de produção, com delineamento de blocos casualizados com quatro repetições e parcelas de $1 \mathrm{~m}^{2}$, com 100 plantas por parcela. Aos 90 dias após o semeio, 20 raízes por parcela foram colhidas e avaliadas para caracteres fenotípicos. Foi realizada análise de variância com determinação da interação entre tratamentos e sistemas de produção, correlações fenotípicas, análise de trilha e os ganhos com as seleções direta e correlacionada. Observouse que a quase totalidade das correlações medianas acima de 0,30, bem como os maiores efeitos diretos da análise de trilha e os maiores ganhos diretos e indiretos estimados, foi repetida nos dois sistemas, indicando que eles foram muito semelhantes na expressão da relação entre os caracteres. Assim, o melhoramento visando aos caracteres avaliados não precisa ser realizado em ambas as áreas de cultivos orgânico e convencional.

Palavras-chave: Daucus carota L., melhoramento, resposta correlacionada.

\section{ABSTRACT}

\section{Relationship among carrot traits in organic and conventional cultivation systems}

The selection strategy and the gain that it will provide allow, in a more efficient way, to direct a breeding program and to predict the success of the chosen selective scheme. The aim of this work was to evaluate the stability of the relationships among phenotypic characteristics of carrot populations cultivated in organic and conventional production systems. The experiments were conducted at Embrapa Vegetables, DF, Brazil. Two breeding lines and four commercial cultivars were planted in November 2007 in both production systems, in a randomized block design with four replications and plots of $1 \mathrm{~m}^{2}$. Ninety days after planting, twenty roots per plot were harvested and evaluated for phenotypic characteristics. The analysis of variance was performed to determine the interaction between treatments and production systems, as well as phenotypic correlations and path analysis. The direct and correlated selection gains were also determined. Almost all of the median correlations above 0.30 and the largest direct effects of path analysis and direct and indirect gains estimated were repeated in both systems, indicating that the systems are very similar in the expression of the relationship among the characteristics. Thus, breeding for these traits do not need to be carried out in areas of both organic and conventional systems.

Key words: Breeding, correlated response, Daucus carota L.

\footnotetext{
Recebido para publicação em maio de 2009 e aprovado em setembro de 2010

${ }^{1}$ Engenheiro Agrônomo, Doutor. Embrapa Hortaliças, Caixa Postal 218, BR 060, Km 09, 70359-970, Gama, Distrito Federal, Brasil. olegario@cnph.embrapa.br.*autor correspondente.

22Engenheiro Agrônomo, Doutor. Embrapa Hortaliças, Caixa Postal 218, BR 060, Km 09, 70359-970, Gama, Distrito Federal, Brasil. jairo@cnph.embrapa.br
} 


\section{INTRODUÇÃO}

O progresso genético direcionado em qualquer espécie está associado à existência de variabilidade genética, à seleção natural e/ou artificial e ao ajuste dos genótipos aos ambientes existentes. Comprovada a presença da variabilidade genética e, sobretudo, o valor dessa em relação à variação não-genética, o processo seletivo assume grande importância no progresso genético, objetivando acumular alelos favoráveis à característica de interesse em determinada população, sendo esse vinculado a uma constante e permanente renovação (Reis et al., 2004). De acordo com a estratégia e o ganho que ela proporcionará, pode-se orientar, de maneira mais efetiva, um programa de melhoramento, bem como predizer o sucesso do esquema adotado, decidindo, com bases científicas, quais esquemas podem resultar em maior ganho genético (Cruz \& Regazzi, 2001).

Além disso, os melhoristas frequentemente enfatizam a seleção para uns poucos caracteres apenas em cada estágio de seleção. Entretanto, é importante saber que o efeito da seleção para um caráter específico pode ocorrer em outros caracteres (Pereira et al. 1994). A existência de associações genéticas entre caracteres determina que quando a seleção é praticada em determinado caráter pode ocasionar alterações em outros, cujo sentido pode ou não ser de interesse para o melhoramento. Dessa forma, o conhecimento das relações entre caracteres é muito importante, podendo-se construir uma estratégia de seleção visando a um caráter de interesse, baseando-se em outros com alta correlação genética, de maiores herdabilidades e de fácil medição ou identificação (Goldenberg, 1968; Baker, 1986; Cruz \& Regazzi, 2001; Silva et al., 2006). A utilização da análise de trilha permite desdobrar os coeficientes de correlação simples em seus efeitos diretos e indiretos, melhorando o entendimento das relações de causa e efeito entre as variáveis estudadas (Barbosa, 1996; Carvalho et al., 2004).

Nos programas de melhoramento de cenoura para o desenvolvimento de novos cultivares, as características avaliadas rendimento e aparência das raízes são muito importantes. Além disso, importância é dada ao teor de âcaroteno, devido a sua influência na saúde humana, por ser precursor da vitamina A. Michalik et al. (1985) mostraram a associação entre a pigmentação mais intensa das raízes, especialmente de sua parte interna, com maior conteúdo de caroteno. Da mesma forma, estudos recentes realizados por Pereira (2002) concluíram que o uso de medidas de cor dos sistemas Hunter e CIELAB pode perfeitamente substituir os métodos laboratoriais "espectrofotométricos e cromatográficos”, que são utilizados para determinação de carotenóides em cenoura.
Atualmente, o mercado consumidor demanda por melhor qualidade das raízes de cenoura, associado à utilização de cultivares com boa sustentabilidade de cultivo, na busca por uma alimentação mais saudável de produtos com boa qualidade visual e nutricional, livre de resíduos de agrotóxicos. Em decorrência dessas demandas, em especial pelo interesse em produtos com baixo nível de resíduos de agrotóxicos e produção menos agressiva ao meio ambiente, a agricultura agroecológica e suas derivações tem tido crescimento acelerado em todo o mundo (Ormond et al., 2002).

As principais diferenças que devem ser observadas no processo de melhoramento de sistemas de cultivos orgânico e convencional estão relacionadas à forma de manejo do solo e de doenças (com agentes químicos) e às práticas de rotação de culturas (Lammerts Van Bueren et al., 1999). Se esses fatores não forem considerados durante o processo de melhoramento, visando a uma possível utilização dos cultivares resultantes em sistemas orgânicos, podem proporcionar diferenças no fenótipo (desempenho) dessas. Isso decorre pelo fato de esses cultivares serem desenvolvidos utilizando-se de práticas divergentes, o que dificultaria a manifestação de todo potencial genético dessas em condições de cultivo orgânico. Entre as características que apresentam desempenho inferior quando cultivares desenvolvidos para sistema de cultivo convencional são utilizados no sistema orgânico estão aquelas relacionadas à nutrição da planta (Wolfe, 2003).

No Brasil, o melhoramento genético visando ao desenvolvimento de cultivares de cenoura adaptados para cultivo em sistemas agroecológicos é incipiente. A grande maioria dos trabalhos de pesquisa até agora realizados estão direcionados à validação de cultivares desenvolvidos primariamente para sistemas convencionais, em condições de cultivo orgânico (Saminez et al., 2002; Resende et al., 2005).

A necessidade da realização de trabalhos com melhoramento exclusivo para sistemas orgânicos, e ainda considerando a existência de diferentes sistemas de cultivo orgânico, é um processo difícil, que exige a definição de estratégias que minimizem os custos e maximizem a eficiência do processo. Além disso, algumas práticas culturais no sistema de cultivo orgânico, como a venda de cenoura em maços com as folhas ou ainda a utilização dessas na produção de compostos, diminuem significativamente a quantidade de inóculo em restos culturais e a ocorrência de doenças foliares em cenoura (Souza, 2006), dificultando a seleção, pois para que esta seja possível é necessária a presença da doença.

O objetivo deste trabalho foi avaliar a estabilidade das relações entre caracteres fenotípicos a partir de populações de cenoura cultivadas em sistemas orgânico e convencional de produção. 


\section{MATERIAL E MÉTODOS}

Os ensaios foram conduzidos no campo experimental da Embrapa Hortaliças no Distrito Federal, em sistemas convencional (utilizado no programa de melhoramento de cenoura) e orgânico de produção (implantado na Embrapa Hortaliças desde 2001). Seis populações de cenoura, duas em fase de melhoramento (derivadas do cultivar Brasília), e quatro cultivares comerciais: Brasília, Alvorada, Esplanada e Carandaí, foram cultivados no verão de 2008 no campo, nos dois sistemas de produção, com delineamento de blocos casualizados, com quatro repetições e parcelas de $1 \mathrm{~m}^{2}$. O desbaste foi realizado 30 dias após semeio, deixando o espaçamento entre plantas de $2 \mathrm{~cm}$ e entre linhas de $20 \mathrm{~cm}$.

Aos 90 dias após semeio, foram colhidas 20 raízes por parcela e avaliados individualmente os caracteres comprimento de raiz (cm); diâmetro da raiz, do xilema da raiz e do floema da raiz (cm), avaliados no terço superior do seu comprimento; comprimento da extensão do ombro verde da raiz (cm); massa da raiz (g); e presença de halo (critério de notas: 1 - ausência, e 2 - presença); formato de ponta da raiz (critério de notas: 1- arredondada, 2- levemente afilada, e 3- afilada); formato de ombro da raiz (critério de notas: 1- cônico, 2- arredondado, 3- plano, e 4- côncavo). Por leitura colorimétrica direta determinou-se o parâmetro $\mathrm{a}^{*}$ para os tecidos xilema e floema de cada raiz, utilizandose o analisador de cor de tristimulus compacto Minolta CR-200b (Minolta Corporation Instrument System Division). Com a utilização do parâmetro a* pode-se determinar o teor de $\beta$-caroteno das raízes de cenoura com segurança (Pereira, 2002).

Os dados foram submetidos à análise de homogeneidade de variância (teste de Bartllet) e de normalidade (Lilliefors). Foi realizada análise de variância para cada sistema e conjunta com informação entre e dentro de população, e determinação da significância de interação entre os sistemas de produção dos diferentes caracteres. Para cada sistema foram estimados os ganhos pela seleção (GS) direta entre e dentro de famílias, com a seleção de $50 \%$ das melhores plantas dentro de populações e entre populações, em que GS = DS.h ${ }^{2}$, e Ds corresponde ao diferencial de seleção, ou diferença entre a média dos selecionados subtraída da média da população base. Foram calculados os ganhos correlacionados, com base nas correlações genéticas entre os caracteres (Cruz \& Regazzi, 2001).

Após diagnóstico de multicolinearidade, foi realizado análise de trilha, de modo a identificar a magnitude dos efeitos diretos e indiretos dos caracteres que influenciam na massa de raízes.

Todas as operações estatísticas foram realizadas utilizando-se o aplicativo computacional Genes (Cruz, 1997).
As magnitudes dos coeficientes de correlação foram classificadas conforme Carvalho et al. (2004): $r=0$ (nula);

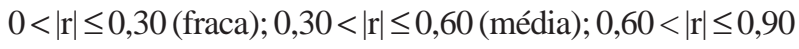
(forte); $0,90<|r| \leq 1$ (fortíssima) e $|r|=1$ (perfeita).

\section{RESULTADOS E DISCUSSÃO}

Os caracteres formato de ponta (FPO) e de ombro (FOM), comprimento da extensão do ombro verde (COV) e presença de halo (PHA) não apresentaram normalidade de distribuição, que é uma das pressuposições da análise de variância. Mesmo com transformação dos dados, foram mantidos na análise apenas para verificar se a seleção por meio de outros caracteres proporcionaria ganhos indiretos nestes caracteres.

Pela análise de variância conjunta dos caracteres que apresentaram normalidade de distribuição (dados não mostrados), pôde-se verificar que todos eles foram significativos na diferenciação das populações, indicando que o desempenho de pelo menos uma das populações foi diferente do das demais para cada caráter. Os caracteres a* do xilema e os diâmetros de raiz, de xilema e de floema apresentaram interação com os sistemas de cultivo, de forma que as populações tiveram comportamento diferenciado nos sistemas orgânico e convencional de cultivo.

No entanto, para os caracteres massa, comprimento de raiz, e a* do floema não seria necessária a implantação de experimentos nos dois sistemas de produção estudados. Para estes caracteres, o desempenho das populações foi semelhante nos dois sistemas de cultivo, e o melhoramento poderia ser feito em quaisquer dos sistemas. Esses resultados são importantes do ponto de vista do melhoramento, pois mesmo havendo diferenças entre sistemas e locais de cultivo, houve comportamento estável das populações avaliadas em relação a importantes componentes de rendimento. Além disso, a nãosignificância da interação possibilita ganhos maiores durante o processo de melhoramento e o desenvolvimento de cultivares com ampla estabilidade (Cruz \& Regazzi, 2001).

Considerando-se que, segundo Wolfe (2003), “a seleção de genótipos ou de uma população para cultivo em sistemas orgânicos deve considerar o desempenho desses em vários ambientes”, o desenvolvimento de cultivares para uso em sistemas orgânicos não pode prescindir das informações relativas à interação genótipos versus ambientes, que são decisivas para o desenvolvimento de cultivares com maior estabilidade.

Como existem diferenças nas metodologias de condução das populações nos diferentes tipos de cultivo agroecológicos, este ensaio poderia ser conduzido com outros sistemas de produção que seguem princípios de 
agroecologia. Utilizando uma população pertencente ao grupo Brasília em cultivos com diretrizes de agriculturas natural e orgânica no Distrito Federal, Vilela (2008) avaliou, com base na média de parcelas, os caracteres COM, DRA, MAS, DXR, DRA, DXR/DRA, FPO, FOM, A*X e A*F. Apesar de COM, A*X, A*F, FPO e FOM terem mostrado interação significativa entre os dois sistemas de produção estudados, os caracteres DRA, MAS, DXR e DXR/DRA, que são muito importantes por serem relacionados com o rendimento de raiz, não apresentaram interação significativa entre os dois sistemas de produção; assim, foi concluído que o melhoramento poderia ser efetuado em apenas um dos sistemas. Esses resultados discordam das afirmações de Lammerts Van Bueren et al. (1999), o qual preconiza que "o melhoramento genético para cultivo orgânico deve ser feito para cada local ou região, em razão de sistemas de produção muito diversos”, sem considerar os aspectos de interação entre ambiente e/ou sistemas.

Além da verificação do comportamento das populações frente aos diferentes ambientes, neste estudo foi também avaliada a estabilidade do comportamento da relação dos caracteres em relação aos demais a que esses são correlacionados.

A correlação indica que o ganho com a seleção para determinado caráter pode ocasionar mudanças em outros caracteres correlacionados, e essa associação pode ou não ser de interresse para o melhorista (Silva et al., 2006). Na diagonal inferior da Tabela 1 estão discriminadas as correlações para o sistema orgânico, e na superior para o sistema convencional. Observa-se que a quase totalidade das correlações medianas acima de 0,30 foi repetida nos dois sistemas, indicando que eles foram muito semelhantes também na expressão da relação entre os caracteres.
Correlações positivas e medianas com o caráter massa de raiz foram verificadas para os caracteres comprimento de raiz e para os diâmetros de raiz, de xilema e de floema, indicando que com a seleção nesses caracteres correlacionados ganhos poderiam ser obtidos em raízes com maior massa. A indicação de que maior diâmetro de raiz determina maior rendimento concorda com Natarajam \& Arumagan (1980) e com McCollum (1971), que encontraram valor de 0,87, e com Alves et al. (2006), valor de 0,54 .

O diâmetro total de raízes correlacionou-se medianamente com os diâmetros de xilema e floema, porém o diâmetro de xilema mostrou maior influência no diâmetro total. Isto indica que quanto maior o diâmetro, principalmente do xilema, maior o diâmetro da raiz. Correlações entre rendimento com diâmetro de xilema $(0,51)$ e entre diâmetro de xilema e floema $(0,35)$ foram verificadas também por Alves et al., (2006).

O parâmetro de cor a* do xilema, além de correlacionar-se positivamente com $\mathrm{a}^{*}$ do floema, correlacionou-se medianamente e negativamente com os diâmetros de raiz e de xilema e ainda com frequência de halo, indicando que raízes mais grossas e com mais halo branco (câmbio) são mais claras, e, portanto, com menor concentração de $\beta$-caroteno. Além disso, correlações negativas e mais fracas, porém próximas de 0,30 , foram verificadas também entre $a^{*}$ do xilema com massa de raiz. Isso pode ter ocorrido devido aos carotenoides serem produzidos até certa fase de desenvolvimento das raízes, enquanto a massa da matéria seca continua sendo acumulada no período em que as folhas produzem fotossíntese, e em razão da acumulação de massa e volume total ser maior nas raízes mais grossas, de forma que os carotenoides estariam diluídos por toda a

Tabela 1. Correlações fenotípicas entre caracteres avaliados em seis populações, duas em fase de melhoramento e quatro cultivares comerciais (Brasília, Alvorada, Esplanada e Carandaí), fontes de variabilidade para utilização no desenvolvimento de novos cultivares, avaliados em sistemas de produção convencional ${ }^{1}$ e orgânico² no Distrito Federal

\begin{tabular}{lccccccccccc}
\hline & FPO $^{\mathbf{1}}$ & FOM & MAS & COM & COV & PHA & DRA & DXR & DFR & A*X $^{*}$ & A*F $^{2}$ \\
\hline FPO $^{2}$ & & 0,09 & $-0,13$ & 0,21 & $-0,12$ & $-0,07$ & $-0,20$ & $-0,11$ & $-0,23$ & 0,26 & 0,17 \\
FOM & 0,05 & & $-0,31$ & $-0,18$ & 0,04 & 0,00 & $-0,30$ & $-0,22$ & $-0,25$ & $-0,01$ & $-0,05$ \\
MAS & $-0,12 *$ & $-0,23$ & & 0,51 & 0,00 & 0,09 & 0,65 & 0,59 & 0,38 & $-0,24$ & 0,05 \\
COM & 0,18 & $-0,15$ & 0,63 & & $-0,04$ & $-0,19$ & 0,28 & 0,27 & 0,13 & 0,12 & 0,22 \\
COV & $-0,11$ & 0,12 & 0,06 & 0,08 & & $-0,02$ & 0,07 & 0,08 & 0,01 & $-0,15$ & $-0,04$ \\
PHA & $-0,14$ & $-0,02$ & 0,22 & $-0,09$ & 0,08 & & 0,27 & 0,37 & $-0,04$ & $-0,54$ & $-0,05$ \\
DRA & $-0,22$ & $-0,15$ & 0,78 & 0,27 & 0,07 & 0,32 & & 0,86 & 0,65 & $-0,35$ & 0,24 \\
DXR & $-0,19$ & $-0,13$ & 0,72 & 0,28 & 0,09 & 0,38 & 0,87 & & 0,18 & $-0,52$ & 0,22 \\
DFR & $-0,16$ & $-0,11$ & 0,46 & 0,11 & 0,01 & 0,05 & 0,67 & 0,22 & & 0,09 & 0,13 \\
A*X & 0,21 & $-0,07$ & $-0,29$ & 0,09 & $-0,16$ & $-0,54$ & $-0,42$ & $-0,53$ & $-0,03$ & & 0,35 \\
A*F & 0,08 & $-0,14$ & 0,21 & 0,18 & $-0,10$ & 0,00 & 0,18 & 0,14 & 0,14 & 0,29 & \\
\hline
\end{tabular}

FPO: formato da ponta; FOM: formato do ombro; MAS: massa; COM: comprimento; COV: comprimento do ombro verde; PHA: presença de halo branco; DRA: diâmetro da raiz; DXR: diâmetro do xilema; DFR: diâmetro do floema; A*X: parâmetro A* do xilema; A*F: parâmetro A* do floema.

*Correlações acima de 0,10 foram significativas a 5\% de probabilidade pelo teste $\mathrm{T}$. 
raiz (Pereira, 2002). Esses resultados indicam que a seleção para maior teor de carotenoides não pode ser efetuada em separado dos caracteres de diâmetro de raiz, que são importantes componentes do rendimento.

A relação entre os caracteres com massa de raiz é entendida com a utilização de análise de trilha (Tabela 2). Da mesma forma que para os valores de correlação, observa-se grande similaridade dos maiores efeitos diretos em ambos os sistemas. Pelos ganhos diretos, comprimento de raiz foi confirmado como o caráter de maior influência em massa de raiz. Ambos os diâmetros de raiz, de xilema e de floema também, apesar de que com magnitude inferior da correlação fenotípica, mantiveram efeito direto em massa de raiz. No entanto, a* de xilema não manteve a correlação com massa; e pelos efeitos indiretos e negativos dos caracteres de diâmetro, verifica-se que a* de xilema não é correlacionado diretamente com massa, e sim apenas indiretamente por meio dos caracteres de diâmetro. Isso ressalta a importância da análise de trilha na verificação da relação entre caracteres, de forma a indicar estratégias de seleção para caracteres que são associados.

Os ganhos diretos e correlacionados (indiretos) com a seleção estão expressos nas Tabelas 3 e 4 para os ganhos entre e dentro de populações, respectivamente.

Pode-se verificar que apesar de os caracteres tipo de ponta e de ombro e frequência de raízes com halo branco e ombro verde não apresentarem normalidade de distribuição, que é uma das pressuposições da análise de variância, a seleção de $50 \%$ das melhores populações e plantas dentro das populações, visando à diminuição no valor desses caracteres, proporcionaria ganhos expressivos em relação à média da amostra inicial, com exceção de formato de ombro, chegando a quase $50 \%$ na seleção para diminuição do ombro verde na seleção entre populações no sistema convencional de cultivo.

Considerando-se os caracteres que apresentaram normalidade de distribuição, a seleção indireta proporcionaria maiores ganhos que a direta para os caracteres: massa de raiz pela seleção em diâmetro de xilema e para diâmetro

Tabela 2. Análise de trilha para massa de raiz com caracteres avaliados em seis populações, duas em fase de melhoramento e quatro cultivares comerciais (Brasília, Alvorada, Esplanada e Carandaí), fontes de variabilidade para utilização no desenvolvimento de novos cultivares, avaliados em sistemas de produção convencional e orgânico no Distrito Federal, demonstrando os efeitos diretos ${ }^{1}$ dos caracteres da coluna ${ }^{2}$ e os indiretos dos caracteres da linha ${ }^{3}$ em massa de raiz

\begin{tabular}{|c|c|c|c|c|c|c|c|c|c|c|}
\hline & FPO $^{2}$ & FOM & COM & $\mathrm{COV}$ & PHA & DRA & DXR & DFR & $\mathbf{A} * \mathbf{X}$ & $\mathbf{A}^{*} \mathbf{F}$ \\
\hline \multicolumn{11}{|c|}{ Convencional } \\
\hline $\mathrm{FPO}^{3}$ & & $-0,01$ & $-0,02$ & 0,01 & 0,01 & 0,02 & 0,01 & 0,02 & $-0,02$ & $-0,01$ \\
\hline FOM & $-0,01$ & & 0,02 & 0,00 & 0,00 & 0,03 & 0,02 & 0,02 & 0,00 & 0,00 \\
\hline COM & 0,08 & $-0,07$ & & $-0,02$ & $-0,07$ & 0,10 & 0,10 & 0,05 & 0,05 & 0,08 \\
\hline $\mathrm{COV}$ & 0,00 & 0,00 & 0,00 & & 0,00 & 0,00 & 0,00 & 0,00 & 0,01 & 0,00 \\
\hline PHA & 0,00 & 0,00 & 0,00 & 0,00 & & 0,00 & $-0,01$ & 0,00 & 0,01 & 0,00 \\
\hline DRA & $-0,05$ & $-0,07$ & 0,07 & 0,02 & 0,06 & & 0,21 & 0,16 & $-0,08$ & 0,06 \\
\hline DXR & $-0,03$ & $-0,05$ & 0,07 & 0,02 & 0,09 & 0,20 & & 0,04 & $-0,12$ & 0,05 \\
\hline DFR & $-0,02$ & $-0,03$ & 0,01 & 0,00 & 0,00 & 0,07 & 0,02 & & 0,01 & 0,01 \\
\hline$A * X$ & $-0,01$ & 0,00 & $-0,01$ & 0,01 & 0,02 & 0,01 & 0,02 & 0,00 & & $-0,01$ \\
\hline$A * F$ & $-0,02$ & 0,01 & $-0,03$ & 0,01 & 0,01 & $-0,03$ & $-0,03$ & $-0,02$ & $-0,04$ & \\
\hline$\overline{E D *}$ & $-0,08^{1}$ & $-0,09$ & 0,38 & $-0,03$ & $-0,02$ & 0,24 & 0,24 & 0,11 & $-0,04$ & $-0,13$ \\
\hline \multicolumn{11}{|c|}{ Orgânico } \\
\hline FPO & & 0,00 & $-0,01$ & 0,01 & 0,01 & 0,01 & 0,01 & 0,01 & $-0,01$ & 0,00 \\
\hline FOM & 0,00 & & 0,01 & $-0,01$ & 0,00 & 0,01 & 0,01 & 0,01 & 0,00 & 0,01 \\
\hline COM & 0,08 & $-0,07$ & & 0,04 & $-0,04$ & 0,12 & 0,13 & 0,05 & 0,04 & 0,08 \\
\hline $\mathrm{COV}$ & 0,00 & 0,00 & 0,00 & & 0,00 & 0,00 & 0,00 & 0,00 & 0,00 & 0,00 \\
\hline PHA & 0,00 & 0,00 & 0,00 & 0,00 & & 0,01 & 0,01 & 0,00 & $-0,02$ & 0,00 \\
\hline DRA & $-0,06$ & $-0,04$ & 0,07 & 0,02 & 0,08 & & 0,23 & 0,18 & $-0,11$ & 0,05 \\
\hline DXR & $-0,05$ & $-0,03$ & 0,07 & 0,02 & 0,10 & 0,22 & & 0,06 & $-0,13$ & 0,04 \\
\hline DFR & $-0,02$ & $-0,01$ & 0,02 & 0,00 & 0,01 & 0,09 & 0,03 & & 0,00 & 0,02 \\
\hline$A * X$ & $-0,01$ & 0,00 & $-0,01$ & 0,01 & 0,03 & 0,03 & 0,03 & 0,00 & & $-0,02$ \\
\hline$A * F$ & 0,00 & 0,00 & 0,01 & 0,00 & 0,00 & 0,01 & 0,00 & 0,00 & 0,01 & \\
\hline ED & $-0,06$ & $-0,06$ & 0,46 & $-0,03$ & 0,03 & 0,26 & 0,25 & 0,14 & $-0,06$ & 0,03 \\
\hline
\end{tabular}

FPO: formato da ponta; FOM: formato do ombro; MAS: massa; COM: comprimento; COV: comprimento do ombro verde; PHA: presença de halo branco; DRA: diâmetro da raiz; DXR: diâmetro do xilema; DFR: diâmetro do floema; A*X: parâmetro A* do xilema; A*F: parâmetro A* do floema.

*ED: efeito direto. 
de floema de raiz pela seleção nas outras medidas de diâmetro (diâmetro total e de xilema) para o sistema orgânico tanto entre quanto dentro de populações. Para o sistema convencional, os ganhos não foram superiores que o ganho direto, mas também foram positivos.

Verifica-se que para ambos os sistemas de produção, tanto pela seleção entre quanto dentro de populações, com a seleção em diâmetro de xilema de raiz obter-se-ia ganhos em diâmetro total de raiz superiores ao ganho pela seleção direta neste caráter. Da mesma forma, a seleção em a* do xilema traria ganhos em a* do floema também superiores ao da seleção direta. Isso se deve, provavelmente, à maior predominância de efeitos de ordem genética em relação à ambiental (maior herdabilidade no sentido amplo) para os caracteres selecionados indiretamente nas condições em que os experimentos foram conduzidos.

A existência de muitas respostas correlacionadas contrárias aos objetivos do melhoramento em relação a todos os caracteres indica que a utilização de índices de seleção seria uma estratégia melhor que a seleção, observando-se cada caráter individualmente.

Dessa forma, pôde-se verificar que com os resultados obtidos na análise de interação de populações com ambientes e também evidenciados pelo comportamento estável das relações entre os caracteres nos sistemas orgânico e convencional, são indicativos de que o melhoramento visando aos caracteres avaliados não precisa ser realizado em ambas as áreas de cultivos orgânico e convencional, possibilitando diminuição de recursos financeiros e de mão de obra empregados no melhoramento. Essa informação, mesmo que preliminar, é muito importante, dada à pequena porcentagem da área de cenoura que é produzida em sistemas agroecológicos e à dificuldade de seleção para queima das folhas em cultivo orgânico, devido à pequena pressão de inóculo e à impossibilidade de inoculação de patógenos nessas áreas para seleção quando os experimentos são realizados em área de produtores.

Tabela 3. Ganhos com a seleção direta para os caracteres (diagonal) ${ }^{1}$, e, pela seleção dos caracteres da linha² são descritos os ganhos correlacionados nos caracteres da coluna ${ }^{3}$, decorrentes da avaliação de seis populações, duas em fase de melhoramento e quatro cultivares comerciais (Brasília, Alvorada, Esplanada e Carandaí), fontes de variabilidade para utilização no desenvolvimento de novos cultivares, avaliados em sistemas de produção convencional e orgânico de produção no Distrito Federal

\begin{tabular}{|c|c|c|c|c|c|c|c|c|c|c|c|}
\hline & $\mathbf{F P O}^{3}$ & FOM & MAS & COM & $\mathrm{COV}$ & PHA & DRA & DXR & DFR & $\mathbf{A}^{*} \mathbf{X}$ & $\mathbf{A}^{*} \mathbf{F}$ \\
\hline \multicolumn{12}{|c|}{ Sistema convencional - seleção entre populações } \\
\hline $\mathrm{FPO}^{2}$ & $-14,81^{1}$ & $-8,14$ & $-8,96$ & 7,89 & 12,73 & 6,45 & $-11,26$ & $-7,51$ & $-9,30$ & 9,78 & 10,14 \\
\hline FOM & $-1,68$ & $-0,94$ & $-2,10$ & $-0,56$ & $-0,01$ & $-0,85$ & 0,36 & 0,46 & $-0,18$ & 0,52 & 2,05 \\
\hline MAS & 8,11 & 9,19 & 11,16 & 0,49 & $-0,95$ & $-2,78$ & 2,60 & 3,94 & $-2,49$ & $-6,75$ & $-12,8$ \\
\hline COM & $-5,64$ & 1,94 & 0,39 & 8,67 & 6,91 & 5,88 & $-8,82$ & $-6,14$ & $-6,74$ & 4,68 & 0,80 \\
\hline $\mathrm{COV}$ & 53,21 & $-0,29$ & 4,41 & $-40,39$ & $-48,87$ & $-28,48$ & 43,76 & 26,00 & 42,84 & $-35,47$ & $-6,07$ \\
\hline PHA & 7,86 & $-5,01$ & 3,74 & $-10,02$ & $-8,30$ & $-19,56$ & 15,71 & 18,57 & $-4,03$ & $-17,07$ & $-6,49$ \\
\hline DRA & 4,95 & $-0,76$ & 1,26 & $-5,42$ & $-4,61$ & $-5,67$ & 5,86 & 5,62 & 1,24 & $-5,65$ & $-3,21$ \\
\hline DXR & 6,65 & $-1,98$ & 3,86 & $-7,60$ & $-5,51$ & $-13,50$ & 11,32 & 13,13 & 2,37 & $-12,92$ & $-6,71$ \\
\hline DFR & 3,46 & 0,32 & $-1,02$ & $-3,50$ & $-3,81$ & 1,23 & 1,05 & $-1,00$ & 4,42 & 0,76 & $-0,12$ \\
\hline$A * X$ & $-10,58$ & $-2,74$ & $-8,07$ & 7,07 & 9,18 & 15,16 & $-13,89$ & $-15,78$ & 2,21 & 16,20 & 10,08 \\
\hline$A^{*} \mathrm{~F}$ & $-2,46$ & $-2,41$ & $-3,46$ & 0,27 & 0,35 & 1,29 & $-1,77$ & $-1,84$ & $-0,08$ & 2,26 & 2,46 \\
\hline \multicolumn{12}{|c|}{ Sistema orgânico - seleção entre populações } \\
\hline FPO & $-6,22^{1}$ & 6,28 & $-1,52$ & 5,37 & 4,87 & 4,79 & $-6,84$ & $-5,61$ & $-5,59$ & 6,15 & 5,01 \\
\hline FOM & 2,83 & 1,40 & $-0,16$ & $-1,30$ & $-2,76$ & $-1,24$ & 1,30 & 1,05 & 1,13 & $-2,22$ & $-3,79$ \\
\hline MAS & 2,24 & 0,51 & 9,25 & 1,95 & $-1,16$ & $-7,77$ & 7,03 & 9,73 & $-5,62$ & $-7,80$ & 1,13 \\
\hline $\mathrm{COM}$ & $-7,59$ & 4,06 & 1,87 & 11,58 & 2,36 & 4,61 & $-7,98$ & $-4,66$ & $-11,95$ & 5,33 & 1,24 \\
\hline $\mathrm{COV}$ & 31,18 & $-39,0$ & 5,05 & $-10,69$ & $-24,92$ & $-15,09$ & 22,89 & 20,36 & 14,20 & $-27,62$ & $-44,6$ \\
\hline PHA & 10,72 & $-6,15$ & 11,79 & $-7,30$ & $-5,28$ & $-18,32$ & 19,17 & 19,83 & 3,92 & $-18,39$ & 0,34 \\
\hline DRA & 5,78 & $-2,44$ & 4,02 & $-4,77$ & $-3,02$ & $-7,24$ & 7,48 & 7,46 & 2,34 & $-7,38$ & $-0,27$ \\
\hline DXR & 10,09 & $-4,17$ & 11,83 & $-5,92$ & $-5,71$ & $-15,91$ & 15,85 & 16,70 & 2,35 & $-15,91$ & 0,47 \\
\hline DFR & 2,59 & $-1,16$ & $-1,77$ & $-3,92$ & $-1,03$ & $-0,81$ & 1,28 & 0,61 & 2,33 & $-1,06$ & $-0,81$ \\
\hline$A * X$ & $-9,98$ & 7,99 & $-8,57$ & 6,11 & 7,00 & 13,33 & $-14,17$ & $-14,37$ & $-3,70$ & 15,23 & 5,53 \\
\hline$A * F$ & $-1,97$ & 3,29 & 0,30 & 0,34 & 2,74 & $-0,06$ & $-0,12$ & 0,10 & $-0,68$ & 1,34 & 3,51 \\
\hline
\end{tabular}

FPO: formato da ponta; FOM: formato do ombro; MAS: massa; COM: comprimento; COV: comprimento do ombro verde; PHA: presença de halo branco; DRA: diâmetro da raiz; DXR: diâmetro do xilema; DFR: diâmetro do floema; A*X: parâmetro A* do xilema; A*F: parâmetro A* do floema.

Rev. Ceres, Viçosa, v. 57, n.5, p. 665-672, set/out, 2010 
Tabela 4. Ganhos com a seleção direta para os caracteres (diagonal) ${ }^{1}$, e, pela seleção dos caracteres da linha ${ }^{2}$ são descritos os ganhos correlacionados nos caracteres da coluna ${ }^{3}$, decorrentes da avaliação de seis populações, duas em fase de melhoramento e quatro cultivares comerciais (Brasília, Alvorada, Esplanada e Carandaí), fontes de variabilidade para utilização no desenvolvimento de novos cultivares, avaliados em sistemas de produção convencional e orgânico de produção no Distrito Federal

\begin{tabular}{|c|c|c|c|c|c|c|c|c|c|c|c|}
\hline & $\mathbf{F P O}^{3}$ & FOM & MAS & COM & $\mathrm{COV}$ & PHA & DRA & DXR & DFR & $\mathbf{A}^{*} \mathbf{X}$ & $\mathbf{A} \mathbf{F}$ \\
\hline \multicolumn{12}{|c|}{ Sistema convencional - seleção dentro populações } \\
\hline $\mathrm{FPO}^{2}$ & $-29,19^{1}$ & $-2,70$ & $-12,46$ & 15,69 & 0,92 & 3,44 & $-17,85$ & $-15,02$ & $-11,45$ & 32,40 & 15,02 \\
\hline FOM & $-3,32$ & $-0,31$ & $-2,92$ & $-1,11$ & 0,00 & $-0,45$ & 0,56 & 0,92 & $-0,22$ & 1,74 & 3,04 \\
\hline MAS & 15,98 & 3,05 & 15,52 & 0,97 & $-0,07$ & $-1,48$ & 4,12 & 7,88 & $-3,07$ & $-22,35$ & $-19,0$ \\
\hline COM & $-11,13$ & 0,64 & 0,54 & 17,25 & 0,50 & 3,14 & $-13,98$ & $-12,27$ & $-8,30$ & 15,49 & 1,19 \\
\hline $\mathrm{COV}$ & 104,9 & $-0,10$ & 6,13 & $-80,32$ & $-3,51$ & $-15,19$ & 69,35 & 51,98 & 52,73 & $-117,5$ & $-8,98$ \\
\hline PHA & 15,49 & $-1,66$ & 5,20 & $-19,93$ & $-0,60$ & $-10,43$ & 24,90 & 37,13 & $-4,96$ & $-56,56$ & $-9,61$ \\
\hline DRA & 9,77 & $-0,25$ & 1,76 & $-10,79$ & $-0,33$ & $-3,03$ & 9,29 & 11,24 & 1,52 & $-18,71$ & $-4,75$ \\
\hline DXR & 13,11 & $-0,66$ & 5,37 & $-15,12$ & $-0,40$ & $-7,20$ & 17,94 & 26,25 & 2,92 & $-42,79$ & $-9,94$ \\
\hline DFR & 6,82 & 0,11 & $-1,42$ & $-6,97$ & $-0,27$ & 0,66 & 1,66 & $-1,99$ & 5,45 & 2,52 & $-0,17$ \\
\hline$A * X$ & $-20,85$ & $-0,91$ & $-11,22$ & 14,06 & 0,66 & 8,09 & $-22,01$ & $-31,55$ & 2,72 & 53,67 & 14,93 \\
\hline $\mathrm{A} * \mathrm{~F}$ & $-4,85$ & $-0,80$ & $-4,80$ & 0,54 & 0,03 & 0,69 & $-2,80$ & $-3,68$ & $-0,09$ & 7,49 & 3,64 \\
\hline \multicolumn{12}{|c|}{ Sistema orgânico - seleção dentro de populações } \\
\hline FPO & $-9,57^{1}$ & 2,65 & $-1,83$ & 13,10 & 0,99 & 4,42 & $-11,13$ & $-11,57$ & $-4,75$ & 20,18 & 7,06 \\
\hline FOM & 4,36 & 0,59 & $-0,19$ & $-3,16$ & $-0,56$ & $-1,14$ & 2,12 & 2,16 & 0,96 & $-7,29$ & $-5,34$ \\
\hline MAS & 3,45 & 0,21 & 11,11 & 4,76 & $-0,24$ & $-7,17$ & 11,43 & 20,04 & $-4,78$ & $-25,59$ & 1,59 \\
\hline COM & $-11,69$ & 1,71 & 2,25 & 28,26 & 0,48 & 4,25 & $-12,99$ & $-9,61$ & $-10,14$ & 17,48 & 1,74 \\
\hline $\mathrm{COV}$ & 47,99 & $-16,5$ & 6,06 & $-26,07$ & $-5,09$ & $-13,92$ & 37,24 & 41,95 & 12,06 & $-90,60$ & $-62,9$ \\
\hline PHA & 16,50 & $-2,60$ & 14,16 & $-17,81$ & $-1,08$ & $-16,89$ & 31,19 & 40,87 & 3,33 & $-60,32$ & 0,48 \\
\hline DRA & 8,90 & $-1,03$ & 4,83 & $-11,64$ & $-0,62$ & $-6,68$ & 12,17 & 15,37 & 1,99 & $-24,20$ & $-0,37$ \\
\hline DXR & 15,53 & $-1,76$ & 14,22 & $-14,45$ & $-1,17$ & $-14,67$ & 25,79 & 34,42 & 2,00 & $-52,19$ & 0,66 \\
\hline DFR & 3,99 & $-0,49$ & $-2,12$ & $-9,55$ & $-0,21$ & $-0,75$ & 2,09 & 1,25 & 1,98 & $-3,46$ & $-1,14$ \\
\hline$A * X$ & $-15,37$ & 3,37 & $-10,30$ & 14,92 & 1,43 & 12,29 & $-23,05$ & $-29,62$ & $-3,14$ & 49,95 & 7,79 \\
\hline$A * F$ & $-3,03$ & 1,39 & 0,36 & 0,84 & 0,56 & $-0,06$ & $-0,20$ & 0,21 & $-0,58$ & 4,38 & 4,94 \\
\hline
\end{tabular}

FPO: formato da ponta; FOM: formato do ombro; MAS: massa; COM: comprimento; COV: comprimento do ombro verde; PHA: presença de halo branco; DRA: diâmetro da raiz; DXR: diâmetro do xilema; DFR: diâmetro do floema; A*X: parâmetro A* do xilema; A*F: parâmetro A* do floema.

\section{CONCLUSÃO}

Observou-se que a quase totalidade das correlações medianas acima de 0,30 , os maiores efeitos diretos da análise de trilha e os maiores ganhos diretos e indiretos estimados foram repetidos nos dois sistemas, indicando que os sistemas foram muito semelhantes na expressão da relação entre os caracteres. Assim, o melhoramento visando aos caracteres avaliados não precisa ser realizado em ambas as áreas de cultivo, orgânico e convencional.

\section{REFERÊNCIAS}

Alves JC da S, Peixoto JR, Vieira JV \& Boiteux LS (2006) Herdabilidade e correlações genotípicas entre caracteres de folhagem e sistema radicular em famílias de cenoura, cultivar Brasília. Horticultura Brasileira, 24:363-365.

Barbosa MHP (1996) Capacidade combinatória e comparação entre critérios de seleção de clones de batata. Tese de Doutorado. Universidade Federal de Lavras, Lavras. 138p.

Baker RJ (1986) Selection indices in plant breeding. Florida, CRC Press. 218p.
Carvalho FIF de, Lorencetti C \& Benin G (2004) Estimativas e implicações da correlação no melhoramento vegetal. Pelotas, Universitária da UFPel. 142p.

Cruz CD (1997) Programa Genes: aplicativo computacional em genética e estatística. Viçosa, Editora UFV. 442p.

Cruz CD \& Regazzi AJ (2001) Modelos biométricos aplicados ao melhoramento genético. Viçosa, Editora UFV. 390p.

Goldenberg JB (1968) El empleo de la correlación en el mejoramento genético de las plantas. Fitotecnia Latinoamericana, 5:1-8.

Lammerts Van Bueren ET, Hulscher M, Haring M, Jongerden J, Van Mansvelt JD, Den Nijs APM \& Ruivenkamp GTP (1999) Sustainable organic plant breeding. Final report: a vision, choices, consequences and steps. Driebergen, Louis Bolk Institut. 60p.

Mccollum GD (1971) Greening of carrot roots (Daucus carota L.): Estimates of heritability and correlation. Euphytica, 20:549-560.

Michalik B, Zabagalo A \& Zukowska E (1985) Investigation of the interdependence of root color and carotene content in carrot variety Selecta. Plant Breeding Abstract, 55:316.

Natarajam S \& Arumagan R (1980) Association analysis of yield and its components in carrot (Daucus carota L.). Madras Agriculture Journal, 9:594-597.

Ormond JGP, Paula SRL de, Filho PF \& Rocha LTM da (2002) Agricultura orgânica: quando o passado é futuro. BNDES Setorial, 15:3-34.

Rev. Ceres, Viçosa, v. 57, n.5, p. 665-672, set/out, 2010 
Pereira AS (2002) Teores de carotenóides totais em cenoura (Daucus carota L.) e sua relação com a coloração das raízes. Tese de Doutorado. Universidade Federal de Viçosa, Viçosa. 128p.

Pereira AS da, Tai GCC, Yada RY, Tarn TR, Souza-Machado V \& Cofin RH (1994) Effect of selection for chip color on some economic traits of potatoes. Plant Breeding, 113:312-317.

Reis EF dos, Reis MS, Cruz CD \& Sediyama T (2004) Comparação de procedimentos de seleção para produção de grãos em populações de soja. Ciência Rural, 34:685-692.

Resende FV, Vieira JV \& Vidal MC (2005) Avaliação de populações de cenoura do programa de melhoramento da Embrapa Hortaliças em sistema orgânico de produção. In: $45^{\circ}$ Congresso Brasileiro de Olericultura, Brasília. Anais, Horticultura Brasileira. CD-ROM.

Saminez TCO, Resende FV, Vieira JV, Couto JR, Paula WS \& Lima $\mathrm{D}$ de $\mathrm{B}$ (2002). Desempenho de cultivares e populações de cenoura em cultivo orgânico no verão do Distrito Federal. In: $42^{\circ}$ Congresso Brasileiro de Olericultura, Brasília. Anais, Horticultura Brasileira. CD-ROM
Silva GO da, Souza VQ de, Pereira A da S, Carvalho FIF de \& Fritsche RN (2006) Early generation selection for tuber appearance affects potato yield components. Crop Breeding and Applied Biotechnology, 6:73-78.

Souza JL de (2006) Manual de horticultura orgânica. 2.ed. atualizado e ampliado. Viçosa, Aprenda fácil. 843p.

Vilela MS (2008) Estimativas de parâmetros genéticos para caracteres de cenoura em sistemas de cultivo agroecológico. Dissertação de mestrado. Universidade Federal de Brasília, Brasília. 68p.

Wolfe MS (2003) Plant breeding, ecology and modern organic agriculture. In: Proceedings of ECO-PB 1rst International symposium on organic seed production and plant breeding, Berlin. Anais, European Consortium of Organic Plant Breeding (ECO-PB). p.21-22. 